\title{
Elemental changes in the hippocampal formation following two different formulas of ketogenic diet: an X-ray fluorescence microscopy study
}

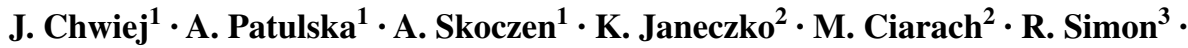 \\ Z. Setkowicz ${ }^{2}$
}

Received: 16 July 2015 / Accepted: 21 October 2015 / Published online: 4 November 2015

(C) The Author(s) 2015. This article is published with open access at Springerlink.com

\begin{abstract}
The main purpose of the following study was the determination of elemental changes occurring within hippocampal formation as a result of high-fat and carbohydrate-restricted ketogenic diet (KD). To realize it, X-ray fluorescence microscopy was applied for topographic and quantitative analysis of $\mathrm{P}, \mathrm{S}, \mathrm{K}, \mathrm{Ca}, \mathrm{Fe}, \mathrm{Cu}, \mathrm{Zn}$ and $\mathrm{Se}$ in hippocampal formations taken from rats fed with two different KDs and naive controls. The detailed comparisons were done for sectors 1 and 3 of the Ammon's, the dentate gyrus and hilus of dentate gyrus. The results of elemental analysis showed that the KDs induced statistically significant changes in the accumulation of $\mathrm{P}, \mathrm{K}, \mathrm{Ca}, \mathrm{Zn}$ and $\mathrm{Se}$ in particular areas of hippocampal formation and these alterations strongly depended on the composition of the diets. Much greater influence on the hippocampal areal densities of examined elements was found for the $\mathrm{KD}$ which was characterized by a lower content of carbohydrates, higher content of fats and increased proportion of unsaturated fatty acids. The levels of $\mathrm{P}, \mathrm{K}$ and $\mathrm{Zn}$ decreased whilst those of $\mathrm{Ca}$ and $\mathrm{Se}$ increased as a result of the treatment with the KDs.
\end{abstract}

Keywords Ketogenic diet - Hippocampal formation · Topographic and quantitative elemental analysis $\cdot \mathrm{X}$-ray fluorescence microscopy $\cdot$ Synchrotron radiation

J. Chwiej

joanna.chwiej@fis.agh.edu.pl

1 Faculty of Physics and Applied Computer Science, AGH University of Science and Technology, Krakow, Poland

2 Institute of Zoology, Jagiellonian University, Krakow, Poland

3 ANKA Synchrotron Radiation Facility, Karlsruhe Institute of Technology, Karlsruhe, Germany

\section{Introduction}

Recently, diets or metabolic therapies are often applied for the treatment of neurodegenerative diseases such as epilepsy, migraine, brain damage, Alzheimer's or Parkinson's diseases, autism, sleep disorders, amyotrophic lateral sclerosis, multiple sclerosis, pain, depression and even cancer [1]. The most famous example of successful diet application against disorders of neurological nature is the use of the ketogenic diet $(\mathrm{KD})$ in patients suffering from intractable epilepsy [2].

Epilepsy, being one of the oldest neurological disorders known to mankind and affecting individuals of all ages, is defined symptomatically by the appearance of spontaneous recurrent seizures [3]. Despite the continued development and release of new antiepileptic drugs, about one-third of people with epilepsy will eventually develop drug refractory seizures [4]. Therefore, there is a great need for better therapeutic strategies. A great body of evidence shows that $\mathrm{KD}$ is a broadly effective treatment for drug-resistant epilepsy [5-9]. This high-fat, low-carbohydrate and usually low-protein diet is mostly used to treat pediatric epilepsies but has satisfactory results also in adolescents and adults [10-13].

Catabolism of fats, being the major caloric source in KD, results in the production of ketone bodies which are alternate energy substrates to glucose [14]. The classical formula developed by Rusell and Wilder (1921) is most widely used [15]. It contains long-chain saturated fatty acids as the main component and slight amount of proteins. In this classical formula of the $\mathrm{KD}$, the ratio of fats to proteins plus carbohydrates is $4: 1$ and is commonly called the ketogenic ratio.

In our previous experiment [16], we investigated effects of the $\mathrm{KD}$ on the elemental and biochemical compositions 
of the hippocampal formation. The diet had its ketogenic ratio set at 9:1. However, it is widely known that various formulas of the KD, having different ketogenic ratios, could be effectively used in clinical antiepileptic therapies [17]. Different health conditions of patients suffering from epilepsy, including children, may be the important reasons to select the diet formulas allowing satisfactory adaptation to the prolonged therapy of those patients who cannot tolerate it well.

Among numerous negative side effects of the long-term $\mathrm{KD}$ application, gastro-intestinal problems are frequently observed [18]. Additionally, levels of micronutrients may be reduced, including, for example, a significant deficiency of selenium, causing serious cardiac disorders [19]. This prompts supplementation of the diet with micronutrients to avoid its definitive withdrawal. Therefore, the need arose to develop a less restrictive but equally effective formula of the KD as, for example, the Atkins diet [20].

This is especially important in treating children who tolerate the KD worse than adults $[18,21]$. According to clinical practice, diets with higher values of the ketogenic ratio have generally greater capacity to ameliorate epileptic symptoms, but they have stronger adverse effects [17]. Thus, clinical and experimental research focus on optimization of the diet formula leading also to better recognition of components critical to the treatment efficacy. The present study aims to examine and distinguish the effects of two KDs characterized by different ketogenic ratios of approximate values 5:1 (KD1) and 9:1 (KD2).

The model of seizures, however, can significantly hamper detection of the dietary effects. Therefore, to avoid the possible interference, this experimental study was performed on the normal brain which was free of seizures occurring in clinical condition. Such studies have not yet been carried out.

Our previous studies carried out on pilocarpine and electroshock models of seizures showed that elemental anomalies occurring as a result of epileptic activity can be limited only to some areas of the hippocampal formation [22-25]. Therefore, analyzing the diet-induced elemental changes, we should use an analytical tool of high spatial resolving power. Relevant spatial resolution can be achieved with the use of synchrotron X-ray fluorescence technique as reported in previous investigations and reviews [26-29].

\section{Materials and methods}

\section{Animals and sample preparation}

Male Wistar rats came from an animal colony of the Department of Neuroanatomy (Institute of Zoology, Jagiellonian University). All the animal-use procedures applied there were approved by the Bioethical Commission of the Jagiellonian University in accordance with international standards. The animals were maintained under conditions of controlled temperature $\left(20 \pm 2{ }^{\circ} \mathrm{C}\right)$ and illumination (12-h light:12-h dark cycle). On the 30th day of postnatal development, the animals were divided into three groups which were afterwards fed either with one of the KDs (KD1 and KD2 groups) or with standard laboratory diet (N group). On the 60th day of postnatal life, the animals were perfused intracardially with physiological saline solution of high analytical quality. The brains were excised, frozen and cut using a cryomicrotome into $12-\mu \mathrm{m}$-thick frontal sections. The slices which contained the dorsal part of the hippocampus were mounted on the $4-\mu \mathrm{m}$-thick Ultralene ${ }^{\circledR}$ foil. Afterwards, they were freeze-dried and till the measurements stored in the ULT freezer at around $-70{ }^{\circ} \mathrm{C}$.

The Ultralene ${ }^{\circledR}$ foil which was used as a sample carrier is free from all, except calcium, the elements under analysis. The content of $\mathrm{Ca}$ in the sample was calculated as the difference between the signal from the tissue and bare foil. Moreover, to verify if Ultralene ${ }^{\circledR}$ foil is really free of impurities, the content of metals in blank (foil expanded on the plastic ring) was measured before the analysis of tissue samples. This measurement confirmed the cleanest of the used sample carrier.

The characteristic of the three groups of animals which were examined in the study is presented in the Table 1 . Additionally, in the Table 2, the contents of main nutrients, fatty acids and selected elements in the three types of diets are shown.

\section{Experimental method and apparatus}

X-ray fluorescence microscopy was used for the qualitative, quantitative and topographic elemental analysis. The measurements were carried out at the FLUO beamline of ANKA [30].

The energy of the beam was tuned to $16 \mathrm{keV}$ using double multilayer monochromator with $\mathrm{W}-\mathrm{Si}$ multilayers at

Table 1 The characteristic of examined animal groups

\begin{tabular}{lllrr}
\hline $\begin{array}{l}\text { Experimental } \\
\text { group }\end{array}$ & $\begin{array}{l}\text { Ketogenic } \\
\text { diet } 1^{*}\end{array}$ & $\begin{array}{l}\text { Ketogenic } \\
\text { diet 2* }\end{array}$ & Standard diet & Perfusion** \\
\hline $\mathrm{N}(n=7)$ & & & + & + \\
$\mathrm{KD} 1(n=6)$ & + & & + \\
$\mathrm{KD} 2(n=6)$ & + & + \\
\hline
\end{tabular}

$n$ number of animals in a group

* KDs 1 and 2 were introduced to rats on the 30th day of their postnatal life

** Perfusion with physiological saline solution was done on the 60th day of rat postnatal development 
Table 2 The content of main nutrients [in (\%)], fatty acids [in (g/ $\mathrm{kg})]$ and selected elements [in $(\mathrm{mg} / \mathrm{kg})]$ in the dry mass of ketogenic and standard diets

\begin{tabular}{llll}
\hline Nutrient & KD1 & KD2 & Standard diet \\
\hline Lipids & 75 & 79 & 5 \\
Carbohydrates & 5 & 1 & 63 \\
Proteins & 9 & 8 & 25 \\
Others & 11 & 12 & 7 \\
SFAs* & 348 & 329 & $-* *$ \\
MUFAs* & 277 & 330 & - \\
PUFAs* & 115 & 86 & - \\
P & 4100 & 5700 & 4100 \\
$\mathrm{~S}$ & 160 & - & 160 \\
$\mathrm{~K}$ & 2200 & 7900 & 2200 \\
$\mathrm{Ca}$ & 7800 & 7900 & 7800 \\
$\mathrm{Fe}$ & 88 & 138 & 88 \\
$\mathrm{Cu}$ & 5.9 & 11 & 5.9 \\
$\mathrm{Zn}$ & 32 & 51 & 32 \\
$\mathrm{Se}$ & 0.41 & 0.10 & 0.41 \\
\hline
\end{tabular}

* SFAs, MUFAs, PUFA-saturated, monounsaturated and polyunsaturated fatty acids

** Lack of information concerning the content of selected ingredient

$2.7 \mathrm{~nm}$ period. The beam was focused with the polycapillary into $13 \mu \mathrm{m}$ spot diameter. The size of the focused beam was measured and optimized by means of knife-edge scans on a silicon chip with 100-nm-thick gold structures. The measured knife edge was fitted to an error function (integral of Gaussian) and the Gaussian parameter sigma was obtained. This parameter was multiplied by 2.35 to get FWHM values.

The flux on the sample was around $10^{11}$ photons/s. The measurements were carried out in air, at room temperature. Silicon drift detector (Ketek Vitus) in connection with a digital signal processor (XIA, Mercury) was used to obtain the fluorescence radiation spectrum emitted by the sample. The detector was positioned at the angle of $45^{\circ}$ in respect to sample and $90^{\circ}$ in respect to the exciting beam. The samples were mapped in two dimensions and the time of single fluorescence spectrum acquisition was $8 \mathrm{~s}$. The step size used during raster scanning was equal to $100 \mu \mathrm{m}$ in both directions and was the compromise between the quality of elemental maps and number of examined cases. It was small enough to obtain the accurate information about the elemental distribution of selected elements in the hippocampal areas of interest and large enough to analyze the whole hippocampal formation in reasonable time what allowed to obtain satisfied statistics of cases. Typically, the number of pixels analyzed per sample was in the range of 800 and 1000 which gave $2-3 \mathrm{~h}$ to measure the area of hippocampal formation.

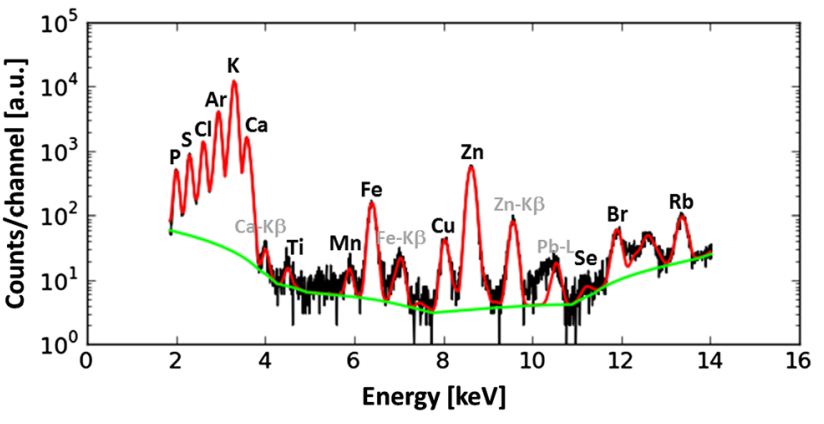

Fig. 1 The raw single spectrum recorded in DG area of rat representing $\mathrm{N}$ group at the typical measurement conditions (black line) together with the fitted spectrum (red line) and background (green line). The high-energy end of the spectrum including peaks of incoherent and coherent scattering was cut off. The used fitting model took into account $\mathrm{K}$-lines of $\mathrm{Ar}$ (present in the air), Ti and $\mathrm{Mn}$ as well as $\mathrm{Pb}$ - $\mathrm{L}$ lines. The occurrence of $\mathrm{Ti}, \mathrm{Mn}$ and $\mathrm{Pb}$ lines in the spectrum probably results from the presence of these elements in the constructing materials used for shields of beamline devices

Reference measurements on the following MICROMATTER XRF calibration standards: $\mathrm{GaP}, \mathrm{CuS}_{\mathrm{x}}, \mathrm{KCl}$, $\mathrm{CaF}_{2}, \mathrm{Ti}, \mathrm{Cr}, \mathrm{Fe}, \mathrm{Cu}, \mathrm{ZnTe}, \mathrm{Ge}, \mathrm{Se}, \mathrm{CsBr}, \mathrm{RbI}$ and $\mathrm{SrF}_{2}$ were performed for spectrometer calibration and elemental sensitivities calculations.

\section{Results}

The analysis of single X-ray fluorescence spectra as well as batch processing of large data sets was carried out using PyMCA software freely available for non-commercial use. One can find the detailed description of the algorithms used in this program in the paper of Sole et al. [31]. In Fig. 1, the exemplary spectrum recorded in the hippocampal formation at the typical measurement condition was presented together with the result of fitting.

The obtained net peak areas of $\mathrm{K}-\alpha$ lines of the analyzed elements and elemental sensitivities evaluated based on measurements of calibration standards were used to calculate elemental areal densities for the examined tissue points, which was in detail presented elsewhere [25].

The first step of the study was the topographic analysis of the distributions of: $\mathrm{P}, \mathrm{S}, \mathrm{K}, \mathrm{Ca}, \mathrm{Fe}, \mathrm{Cu}, \mathrm{Zn}$ and $\mathrm{Se}$ in the analyzed tissue sections. One slice of the dorsal part of the hippocampal formation per each animal (the number of animals used in the study is placed in Table 1) was examined. In Fig. 2, one can see the comparison of the elemental maps obtained for selected rats representing N, KD1 and KD2 groups.

As it can be seen from Fig. 2, most of the elements present quite homogenous distributions within hippocampal formation. The exceptions are $\mathrm{Fe}$ and $\mathrm{Zn}$. The increased 


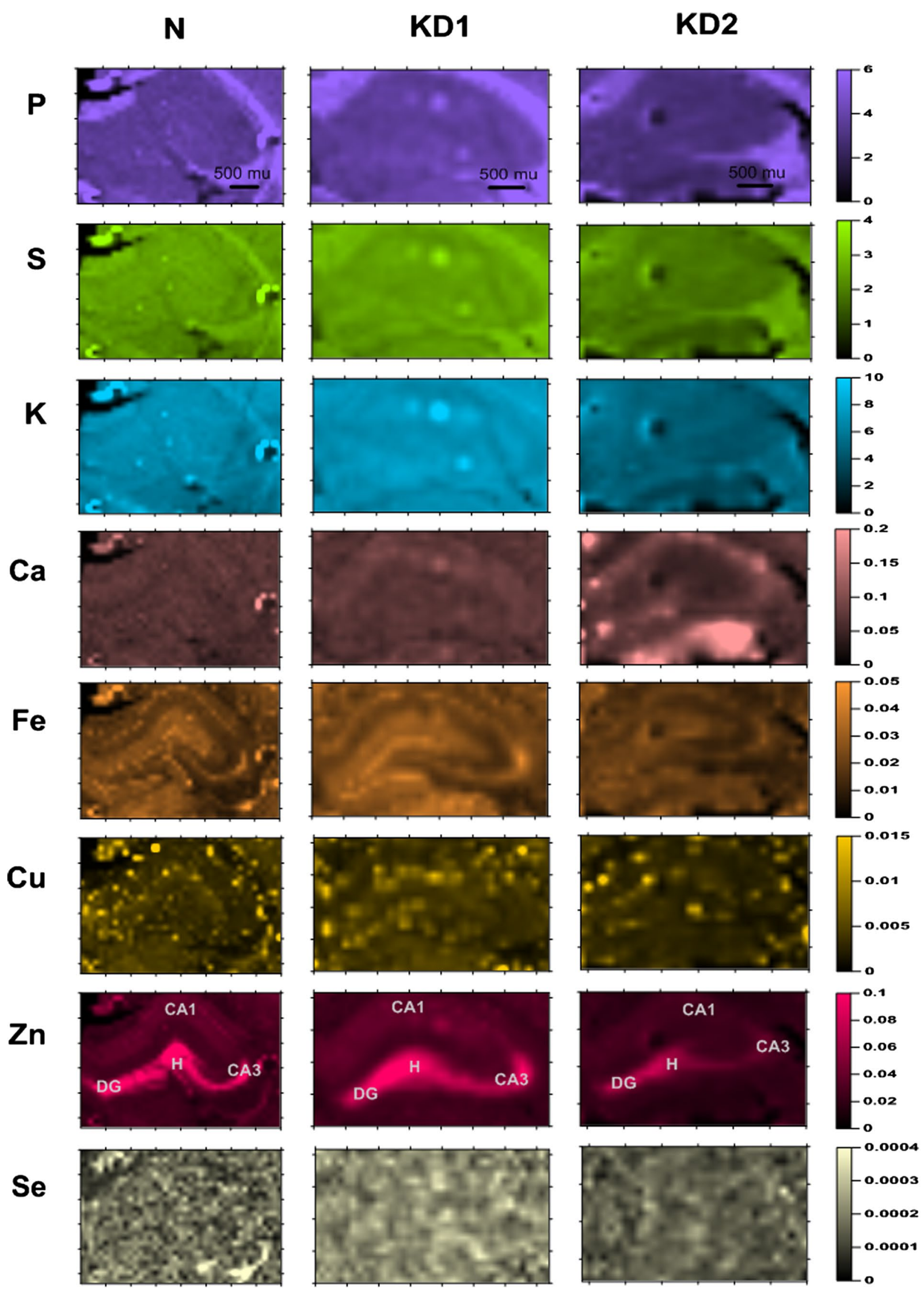

Fig. 2 Elemental maps obtained for hippocampal formations from selected animals representing N, KD1 and KD2 groups. The data were interpolated using the Kriging method [32]. Scales display areal densities of the elements in $\mu \mathrm{g} / \mathrm{cm}^{2}$ 
accumulation of these elements is connected with particular cells or cellular layers. For example, $\mathrm{Zn}$ is present at high concentrations in the synaptic vesicles of hippocampal mossy fibers. The preliminary comparisons of the elemental maps obtained for the three examined animal groups showed increased $\mathrm{Ca}$ level and decreased $\mathrm{Zn}$ level in selected areas of hippocampal formation after the treatment with KD2. As one can see it in Fig. 2, such changes were not noticed for animals fed with KD1.

To confirm statistical significance of the observed changes, the quantitative analysis of selected hippocampal regions followed by appropriate statistical tests was carried out. For all examined samples the mean elemental areal densities were calculated for sectors 1 and 3 of the Ammon's horn (CA1 and CA3, respectively), the dentate gyrus (DG) and hilus of DG $(\mathrm{H})$. The preliminary identification of the mentioned areas was based on the microscopic view of the unstained slice dedicated to elemental studies. In case of any doubt, additional comparisons with the neighboring slice subjected to hematoxylin-eosin staining were done.

One can see the localization of CA1, CA3, DG and H areas within the hippocampal formation in the $\mathrm{Zn}$ maps presented in Fig. 2. To compare rats fed with different diets, the median areal densities of elements in these groups were evaluated and presented in Table 3. Statistical significance of differences between medians was tested using nonparametric $U$ Mann-Whitney test at the confidence level of $95 \%$. To better demonstrate KD-induced changes in elemental composition, the percentage differences (PC) in elemental accumulation were calculated according to the formula (1) and are presented in Fig. 3.

$\mathrm{PC}_{\mathrm{KD}}^{e}[\%]=\frac{\mathrm{AD}_{\mathrm{KD}}^{e}-\mathrm{AD}_{\mathrm{N}}^{e}}{\mathrm{AD}_{\mathrm{N}}^{e}} \times 100$

where $\mathrm{PC}_{\mathrm{KD}}^{e}$ is the ketogenic diet $(K D)$-induced percentage change of areal density of element $e, \mathrm{AD}_{\mathrm{KD}}^{e}$ is the median areal density of element $e$ in $K D$-treated animal, $\mathrm{AD}_{\mathrm{N}}^{e}$ is the median areal density of element $e$ in animal fed with standard laboratory diet.

As one can notice from Table 3 and Fig. 3, KD1 and KD2 introduced different elemental changes in examined areas of hippocampal formation. The rats fed with the KD1 showed increased levels of Se $(>15 \%)$ in all examined regions but the only region where this relation was statistically significant was the internal area of DG (19\% increase).

More statistically significant differences were noticed when KD2 and N groups were compared. Higher levels of $\mathrm{Ca}$ in $\mathrm{CA} 3$, DG and its internal area were found in KD2fed rats and the percentage increase of $\mathrm{Ca}$ areal density was $50 \%$ or more despite the almost equal Ca contents in both diets. The opposite relation was found for $\mathrm{Zn}$. Despite higher $\mathrm{Zn}$ content in KD2, the level of this element in KD2 group was significantly diminished in CA3 and DG comparing to animals on standard diet.

Moreover, KD2 group presented lower, in comparison to animals on standard diet, areal densities of $\mathrm{P}$ and K. For both elements this relation was statistically significant in CA3 area and for P additionally in DG.

\section{Discussion and conclusions}

In the study, X-ray fluorescence microscopy was used to follow KD-induced changes in elemental composition of the hippocampal formation. The quantitative elemental analysis was done for CA1, CA3, DG and $\mathrm{H}$ hippocampal areas. Rats fed with two different ketogenic diets (KD1 and KD2) were compared with normal animals on standard laboratory diet. Commercially available KD2 is characterized by a lower content of carbohydrates, higher content of fats and increased proportion of unsaturated fats in them comparing to KD1. Moreover, KD1 and KD2 differed in the content of some of the analyzed elements, which one can in detail see in Table 2.

Application of KD1 introduced only one change in the elemental composition of hippocampal formation. Higher areal density of Se in the internal area of DG was found in KD1-fed rats comparing to controls. The comparison of $\mathrm{KD} 2$ and $\mathrm{N}$ groups did not show any differences in Se level what may result from the fact that the content of Se in KD2 was 4 times lower than in the standard laboratory diet.

Selenium being a part of selenoproteins is an essential nutrient of fundamental importance to human biology. Some of the selenoproteins possess antioxidant activities which means that they protect cells against oxidative stress and increase their survival in pathological conditions [33]. Selenocysteine-containing glutathione peroxidases are, together with superoxide dismutases and catalase, the most important antioxidant enzymes [33].

Oxidative stress meaning an imbalance in oxidant and antioxidant homeostasis is strongly implicated in a number of neuronal disorders including Alzheimer's and Parkinson's diseases, stroke-related brain damage and seizure disorders [33, 34]. There is also a significant link between Se and epilepsy [33, 35-37]. The plasma level of Se and blood glutathione peroxidase activity were severely reduced in children with intractable seizures [38] and supplementation with Se helped to control seizures [37]. Application of Se reduced tissue damage and normalized EEG [39] in animal model with $\mathrm{Fe}^{2+}$-induced epileptic seizures. In the other study, carried out on the pentylenetetrazol model of seizures, it was shown that dietary administration of Se attenuated the breakdown of the blood-brain barrier [40]. 
Table 3 Median areal densities (in $\mu \mathrm{g} / \mathrm{cm}^{2}$ ) of elements recorded for animals on ketogenic (KD1 and KD2) and standard (N) laboratory diets

\begin{tabular}{|c|c|c|c|c|c|c|c|c|}
\hline & \multicolumn{8}{|c|}{$\mathbf{N}$} \\
\hline & $\mathbf{P}$ & $S$ & $K$ & $\mathrm{Ca}$ & $\mathrm{Fe}$ & $\mathrm{Cu}$ & $\mathrm{Zn}$ & Se \\
\hline \multirow{2}{*}{ CA1 } & 3.6 & 2.4 & 6 & 0.07 & 0.020 & 0.0031 & 0.036 & 0.00016 \\
\hline & $(0.8)^{*}$ & (0.7) & $(2)$ & $(0.02)$ & $(0.005)$ & $(0.0003)$ & (0.009) & $(0.00004)$ \\
\hline \multirow{2}{*}{ CA3 } & 4 & 2.4 & 6 & 0.08 & 0.025 & 0.0033 & 0.07 & 0.00017 \\
\hline & (1) & $(0.6)$ & (2) & $(0.03)$ & $(0.008)$ & $(0.0006)$ & $(0.03)$ & $(0.00007)$ \\
\hline \multirow{2}{*}{ DG } & 3.6 & 2.2 & 6 & 0.07 & 0.024 & 0.004 & 0.07 & 0.00017 \\
\hline & $(0.4)$ & $(0.2)$ & (1) & $(0.01)$ & $(0.005)$ & $(0.002)$ & $(0.03)$ & $(0.00006)$ \\
\hline \multirow{4}{*}{ H } & 3.8 & 2.5 & 7 & 0.07 & 0.019 & 0.0033 & 0.08 & 0.00018 \\
\hline & $(0.6)$ & $(0.4)$ & (2) & $(0.02)$ & $(0.004)$ & $(0.0006)$ & $(0.02)$ & $(0.00005)$ \\
\hline & \multicolumn{8}{|c|}{ KD1 } \\
\hline & $\mathbf{P}$ & $S$ & $K$ & $\mathrm{Ca}$ & $\mathrm{Fe}$ & $\mathrm{Cu}$ & $\mathrm{Zn}$ & Se \\
\hline \multirow{2}{*}{ CA1 } & 3.5 & 2.4 & 6.6 & 0.075 & 0.022 & 0.004 & 0.036 & 0.00019 \\
\hline & $(0.4)$ & $(0.3)$ & $(0.8)$ & $(0.004)$ & $(0.004)$ & $(0.003)$ & $(0.003)$ & $(0.00008)$ \\
\hline \multirow{2}{*}{ CA3 } & 3.9 & 2.4 & 6.8 & 0.079 & 0.031 & 0.0029 & 0.09 & 0.00022 \\
\hline & $(0.6)$ & $(0.2)$ & (0.7) & (0.007) & $(0.007)$ & $(0.0006)$ & $(0.02)$ & $(0.00003)$ \\
\hline \multirow{2}{*}{ DG } & 3.4 & 2.1 & 6.3 & 0.066 & 0.027 & 0.005 & 0.07 & 0.00020 \\
\hline & $(0.5)$ & $(0.2)$ & $(0.6)$ & $(0.008)$ & $(0.004)$ & $(0.003)$ & $(0.01)$ & $(0.00003)$ \\
\hline \multirow{4}{*}{ H } & 3.8 & 2.4 & 7 & 0.070 & 0.021 & 0.0039 & 0.081 & 0.00021 \\
\hline & $(0.8)$ & $(0.3)$ & (1) & (0.008) & $(0.003)$ & $(0.0007)$ & $(0.005)$ & $(0.00005)^{* *}$ \\
\hline & \multicolumn{8}{|c|}{ KD2 } \\
\hline & $\mathbf{P}$ & $S$ & $K$ & $\mathrm{Ca}$ & $\mathrm{Fe}$ & $\mathrm{Cu}$ & $\mathrm{Zn}$ & Se \\
\hline \multirow{2}{*}{ CA1 } & 3.2 & 2.3 & 6 & 0.11 & 0.020 & 0.004 & 0.032 & 0.00017 \\
\hline & (0.7) & $(0.6)$ & (2) & $(0.04)$ & $(0.006)$ & $(0.002)$ & $(0.006)$ & $(0.00005)$ \\
\hline \multirow{2}{*}{ CA3 } & 3.2 & 2.2 & 5 & 0.13 & 0.027 & 0.0033 & 0.052 & 0.00020 \\
\hline & $(0.7)^{*}$ & $(0.5)$ & (2) & $(0.05)$ & $(0.005)$ & $(0.0004)$ & $(0.008)$ & $(0.00004)$ \\
\hline \multirow{2}{*}{ DG } & 3.3 & 2.1 & 6 & 0.10 & 0.024 & 0.004 & 0.057 & 0.00018 \\
\hline & $(0.8)$ & (0.7) & (2) & $(0.01)$ & $(0.004)$ & $(0.002)$ & $(0.007)$ & $(0.00003)$ \\
\hline \multirow{2}{*}{ H } & 4 & 2.4 & 6 & 0.10 & 0.020 & 0.005 & 0.06 & 0.00018 \\
\hline & (1) & (0.9) & $(2)$ & $(0.02)$ & $(0.005)$ & $(0.003)$ & $(0.02)$ & $(0.00004)$ \\
\hline
\end{tabular}

* The uncertainties of median values were calculated as the interquartile spans and presented in parentheses

** Statistically significant (at the significance level of $5 \%$ ) differences found for KD1 and KD2 groups comparing to controls were in bold and, additionally, increases were presented in green whilst decreases in red

Much more statistically significant changes in the elemental composition of hippocampal formation were introduced through KD2. KD2-induced anomalies manifested mostly in CA3 and DG. In both hippocampal areas, lower areal densities of $\mathrm{P}$ and $\mathrm{Zn}$ and higher levels of $\mathrm{Ca}$ were found for KD2 group comparing to controls. Moreover, the decreased level of $\mathrm{K}$ in $\mathrm{CA} 3$ and increase of $\mathrm{Ca}$ in the hilus of DG were noticed in animals fed with KD2.

The most surprising effect of KD2 was the increased level of $\mathrm{Ca}$ in all the analyzed hippocampal areas (in CA1 not statistically significant). Although the contents of $\mathrm{Ca}$ in the three diets were comparable, hippocampal areal 
Increase/decrease of $\mathrm{P}$ areal density [\%]

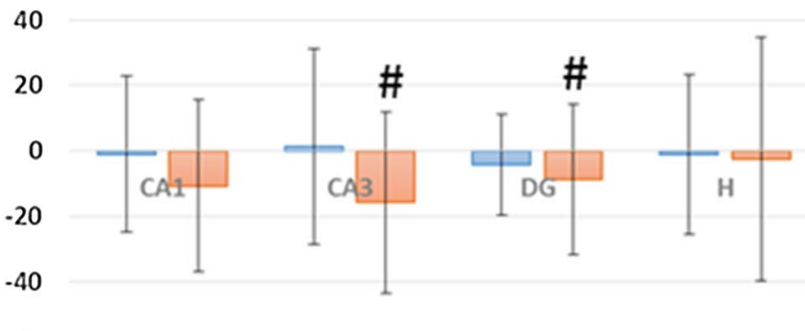

$-60$

$\square \mathrm{KD} 1 \square \mathrm{KD2}$

Increase/decrease of $\mathrm{K}$ areal density [\%]

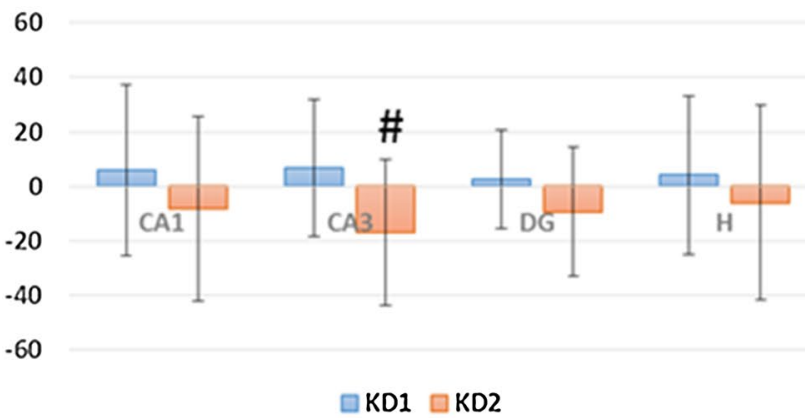

Increase/decrease of Fe areal density [\%]

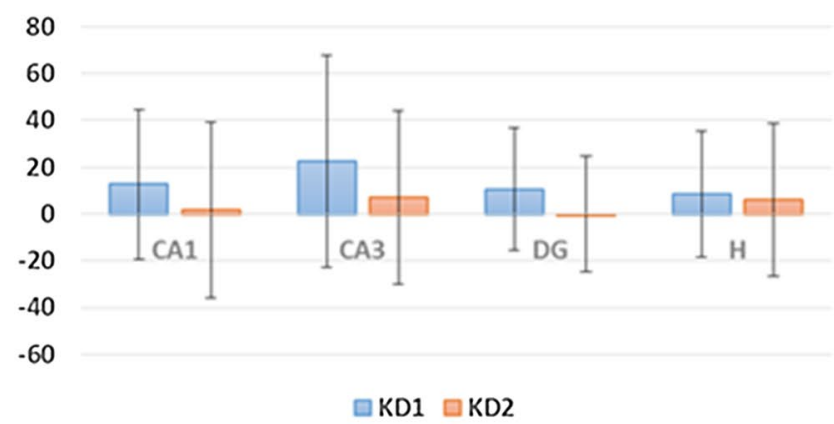

Increase/decrease of $\mathrm{Zn}$ areal density [\%]

100

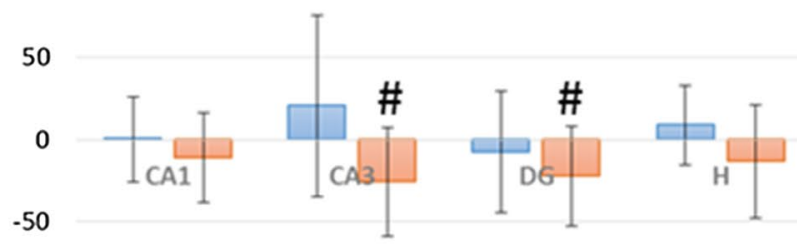

$-100$

$\square K D 1 \square K D 2$

Fig. 3 The percentage changes in the elemental composition of CA1, CA3, DG and H hippocampal areas induced by KD1 and KD2. Positive value means higher whilst negative means lower content of element in KD1 or KD2 group comparing to controls on standard laboratory diet. Statistically significant differences between KD1 and N
Increase/decrease of S areal density [\%]

40

20

0

$-20$

$-40$

.60

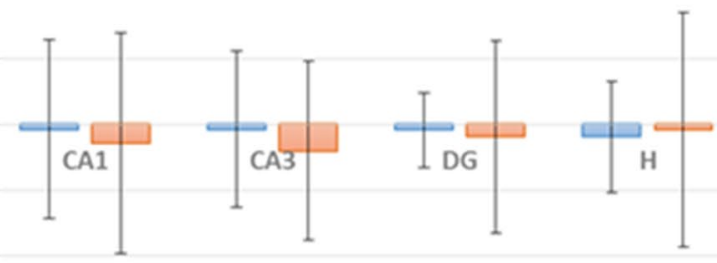

$\square \mathrm{KD} 1 \square \mathrm{KD2}$

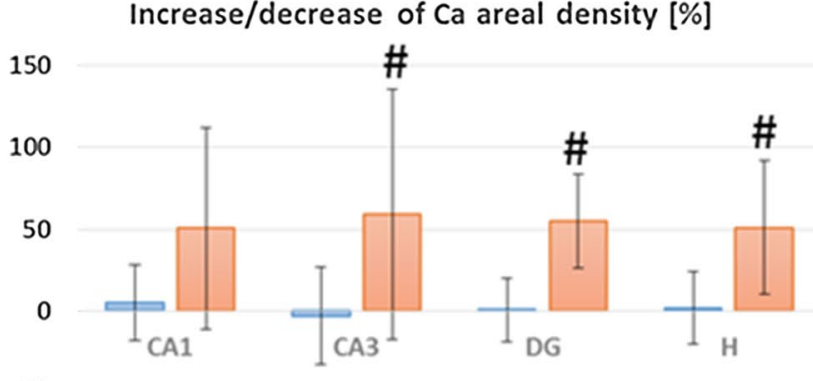

$-50$

$\square K D 1 \square K D 2$

Increase/decrease of Cu areal density [\%]

200

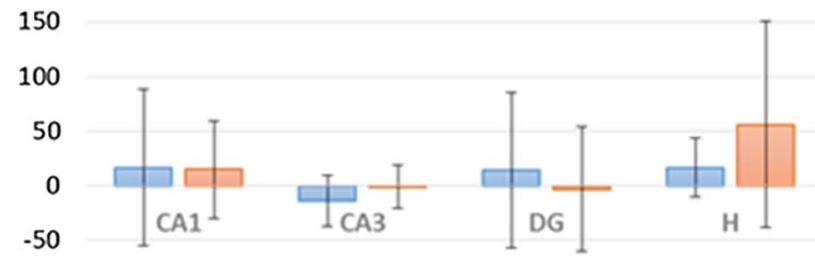

$-100$

$\square \mathrm{KD} 1 \square \mathrm{KD} 2$

Increase/decrease of Se areal density [\%]

100

80

60

40

20

0

$-20$

$-40$

$-60$

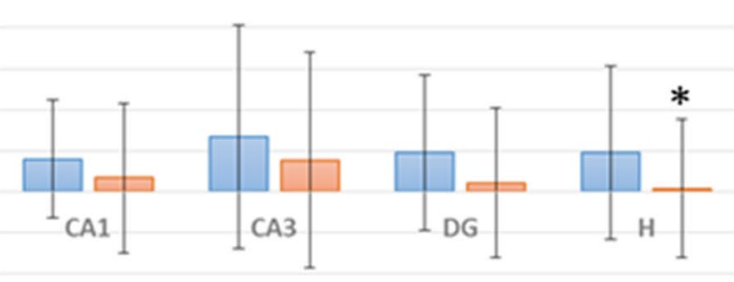

groups were marked with asterisk whilst between KD2 and N groups with hash. The uncertainties were evaluated according to the law of propagation of uncertainties and the calculations were based on the data presented in the Table 3 
densities of this element increased only in KD2-fed rats for which they were 50-60\% higher comparing to control animals. Such relation was not found for KD1 group which may suggest that an increased Ca level in KD2-fed rats was an effect of the action of the other components of this diet.

The existing literature suggests that polyunsaturated fatty acids (PUFAs) from KD should rather reduce $\mathrm{Ca}$ influx and decrease reactive oxygen species production than elevate their levels [5]. This results from the fact that PUFAs induce the activity of mitochondrial uncoupled proteins (UCPs) which leads to a reduction of the proton gradient across the inner mitochondrial membrane [5, 41, 42]. From the other side, according to Hawkes et al., hypercalcemia may be an uncommon complication of the KD [43].

The hippocampal level of $\mathrm{Ca}$ increases as a result of seizures [22-24]. Epileptic seizures induce excessive glutamate release which activates postsynaptic NMDA receptors and triggers receptor-mediated $\mathrm{Ca}^{2+}$ ions influx [44]. This increase in the concentration of $\mathrm{Ca}$ ions promotes a cascade of further events that finally lead to the excitotoxicity and cell death [45].

Therefore, KD2 introduced in the hippocampal areas similar anomalies in $\mathrm{Ca}$ accumulation that are observed as a result of seizure activity.

The treatment of animals with the KD2 induced statistically significant decrease of $\mathrm{Zn}$ areal density in CA3 and DG areas. Analogous effect was found in our previous study carried out on the pilocarpine model of epilepsy. In the acute phase of pilocarpine-evoked seizures, the level of $\mathrm{Zn}$ was reduced in both the mentioned hippocampal areas [22].

It can be assumed that the long-term influence of KD on the nervous tissue produced changes similar to those occurring after the onset of seizures. Consequently, these changes could modify so much the properties of the tissue that it was no longer able to develop a complete seizure response after administration of the chemoconvulsant. These changes appear to resemble preconditioning phenomena described in numerous reports, including that by Kosonowska et al. [46]. The present paper does not identify the mechanisms underlying the observed phenomenon, but may suggest that their action may not necessarily be of neuroprotective nature.

Zinc is an essential nutrient which can be supplied to the brain through the blood-brain and blood-cerebrospinal fluid barriers [47]. Although there is many links between $\mathrm{Zn}$ and epilepsy, the role of this element in the etiology and manifestations of seizures has still been very enigmatic [47, 48]. The intracerebroventricular administration of $\mathrm{Zn}$ ions causes epileptic seizures in rats and their increased level was found in the inborn audiogenic mouse $[49,50]$. On the other hand, subcutaneous injections of this element reduce the frequency of noise-induced clonic and tonic seizures and deaths in mice, but had no significant effect on the occurrence and severity of kainic acidinduced seizures in rats [51]. Fukahori et al. showed, moreover, that dietary $\mathrm{Zn}$ loading diminished, whilst $\mathrm{Zn}$ deficiency increased seizure susceptibility in epilepsy mice [52]. Therefore, as it can be easily seen, zinc in seizures may have both pro- and anticonvulsant effects. Moreover, this dual action appears to be dose dependent [48].

The higher level of $\mathrm{Ca}$ and lower areal density of $\mathrm{Zn}$ which were observed in KD2-fed animals point that $\mathrm{KD}$ may induce in the hippocampal formation similar conditions as epileptic seizures do. Therefore, anticonvulsant activity of KD does not have to be associated with its neuroprotective effect on the brain. Another reason is that the $\mathrm{KD}$ was introduced in animals which were too young and, therefore, its long-term application disturbed their brain development. Also, it appears possible that some other mechanisms are involved in the action of KD and the diet targets other cellular elements of the nervous tissue including astrocytes. For detailed exploration of the problem, further studies are necessary.

The results presented in the study did not show any KDinduced changes in $\mathrm{S}, \mathrm{Fe}$ and $\mathrm{Cu}$ hippocampal accumulation. Animals fed with KD2 presented lower, in comparison to animals on standard diet, areal densities of $\mathrm{P}$ and $\mathrm{K}$. For both elements this relation was statistically significant in CA3 area and for P additionally in DG. The change of $\mathrm{K}$ level may be connected with the action of PUFAs and/or ketone bodies. Recently, it has been suggested that PUFAs, in conjunction with ketone bodies, may activate a lipidsensitive class of $\mathrm{K}_{2} \mathrm{P}$ potassium channels and enhance the activity of the $\mathrm{Na}+/ \mathrm{K}+-$ ATPase (sodium pump) $[6,53]$. In this context, it is necessary to mention that both increased accumulation of ketone bodies and increased unsaturation level of lipids in the hippocampal formations were previously found for rats fed with KD1 and KD2, which was in detail described elsewhere [16, 54].

Assuming, the results presented in this paper showed that KD may induce significant changes in accumulation of selected elements. The changes depend on the composition of high-fat diets and seem to be much stronger in case of the diet with higher ketogenic ratio.

Acknowledgments This work was supported by the Polish Ministry of Science and Higher Education, the Foundation for Polish Science-PARENT-BRIDGE Programme co-financed by the European Union within European Regional Development Fund (POMOST/2013-8/3) and the statutory research of the Institute of Zoology (Jagiellonian University) K/ZDS/0004832. We acknowledge the Synchrotron Light Source ANKA for provision of instruments at the beamline FLUO (proposals no. A2013-022-004153 and A2014024-006393). We thank also MSc Joanna Osoba for animal care and food delivery. 
Open Access This article is distributed under the terms of the Creative Commons Attribution 4.0 International License (http://creativecommons.org/licenses/by/4.0/), which permits unrestricted use, distribution, and reproduction in any medium, provided you give appropriate credit to the original author(s) and the source, provide a link to the Creative Commons license, and indicate if changes were made.

\section{References}

1. Stafstrom CE, Rho JM (2012) The ketogenic diet as a treatment paradigm for diverse neurological disorders. Front Pharmacol 9:3-59

2. Bertoli S, Battezzati A, Tagliabue A (2014) Ketogenic diet in children with intractable epilepsy: what about resting energy expenditure and growth? Dev Med Child Neurol 56:806-807

3. Banerjee PN, Filippi D, Allen Hauser W (2009) The descriptive epidemiology of epilepsy-a review. Epilepsy Res 85:31-45

4. Sillanpää M, Schmidt D (2006) Natural history of treated childhood-onset epilepsy: prospective, long-term population-based study. Brain 29:617-624

5. Freeman J, Veggiotti P, Lanzi G, Tagliabue A, Perucca (2006) The ketogenic diet: from molecular mechanisms to clinical effects. Epilepsy Res 68:145-180

6. Bough KJ, Rho JM (2007) Anticonvulsant mechanisms of the ketogenic diet. Epilepsia 48:43-58

7. Bough KJ, Wetherington J, Hassel B, Pare JF, Gawryluk JW, Greene JG, Shaw R, Smith Y, Geiger JD, Dingledine RJ (2006) Mitochondrial biogenesis in the anticonvulsant mechanism of the ketogenic diet. Ann Neurol 60:223-235

8. Yudkoff M, Daikhin Y, Nissim I, Lazarow A, Nissim I (2004) Ketogenic diet, brain glutamate metabolism and seizure control. Prostaglandins Leukot Essent Fatty Acids 70:277-285

9. Lee PR, Kossoff EH (2011) Dietary treatments for epilepsy: management guidelines for the general practitioner. Epilepsy Behav 21:115-121

10. Sirven J, Whedon B, Caplan D, Liporace J, Glosser D, O'Dwyer J, Sperling MR (1999) The ketogenic diet for intractable epilepsy in adults: preliminary results. Epilepsia 40:1721-1726

11. Nordli DR Jr, Kuroda MM, Carroll J, Koenigsberger DY, Hirsch LJ, Bruner HJ, Seidel WT, De Vivo DC (2001) Experience with the ketogenic diet in infants. Pediatrics 108:129-133

12. Mady MA, Kossoff EH, McGregor AL, Wheless JW, Pyzik PL, Freeman JM (2003) The ketogenic diet: adolescents can do it, too. Epilepsia 44:847-851

13. Coppola G, Veggiotti P, Cusmai R, Bertoli S, Cardinali S, Dionisi-Vici C, Elia M, Lispi ML, Sarnelli C, Tagliabue A, Toraldo C, Pascotto A (2002) The ketogenic diet in children, adolescents and young adults with refractory epilepsy: an Italian multicentric experience. Epilepsy Res 48:221-227

14. Puchowicz MA, Zechel JL, Valerio J, Emancipator DS, Xu K, Pundik S, LaManna JC, Lust WD (2008) Neuroprotection in diet-induced ketotic rat brain after focal ischemia. J Cereb Blood Flow Metab 28:1907-1916

15. Wilder RM (1921) The effects of ketonemia on the course of epilepsy. Mayo Clin Proc 2:307-308

16. Chwiej J, Skoczen A, Matusiak K, Janeczko K, Patulska A, Sandt C, Simon R, Ciarach M, Setkowicz Z (2015) The influence of the ketogenic diet on the elemental and biochemical compositions of the hippocampal formation. Epilepsy Behav 49:40-46

17. Wirrell EC (2008) Ketogenic ratio, calories and fluids: do they matter? Epilepsia 49:17-19
18. Levy RG, Cooper PN, Giri P (2012) Ketogenic diet and other dietary treatments for epilepsy. Cochrane Database Syst Rev 14:CD001903

19. Sirikonda NS, Patten WD, Phillips JR (2012) Ketogenic diet: rapid onset of selenium deficiency-induced cardiac decompensation. Mullett CJ Pediatr Cardiol 33:834-838

20. Miranda MJ, Mortensen M, Povlsen JH, Nielsen H, Beniczky S (2011) Danish study of a modified Atkins diet for medically intractable epilepsy in children: can we achieve the same results as with the classical ketogenic diet? Seizure 20:151-155

21. Auvin S (2012) Should we routinely use modified Atkins diet instead of regular ketogenic diet to treat children with epilepsy? Seizure 21:237-240

22. Chwiej J, Winiarski W, Ciarach M, Janeczko K, Lankosz M, Janeczko K, Rickers-Appel K, Setkowicz Z (2008) The role of trace elements in the pathogenesis and progress of pilocarpineinduced epileptic seizures. J Biol Inorg Chem 13:1267-1274

23. Chwiej J, Janeczko K, Marciszko M, Czyzycki M, Rickers K, Setkowicz Z (2010) Neuroprotective action of FK-506 (tacrolimus) after seizures induced with pilocarpine: quantitative and topographic elemental analysis of brain tissue. J Biol Inorg Chem 15:283-289

24. Chwiej J, Kutorasinska J, Janeczko K, Gzielo-Jurek K, Uram L, Appel K, Simon R, Setkowicz Z (2012) Progress of elemental anomalies of hippocampal formation in the pilocarpine model of temporal lobe epilepsy-X-ray fluorescence microscopy study. Anal Bioanal Chem 404:3071-3080

25. Chwiej J, Gabrys H, Janeczko K, Kutorasinska J, Gzielo-Jurek K, Matusiak K, Appel K, Setkowicz Z (2014) Elemental anomalies in the hippocampal formation after repetitive electrical stimulation: an X-ray fluorescence microscopy study. J Biol Inorg Chem 19:1209-1220

26. Snigireva I, Snigirev A (2006) X-Ray microanalytical techniques based on synchrotron radiation. J Environ Monit 8:33-42

27. Majumdar S, Peralta-Videa JR, Castillo-Michel H, Hong J, Rico CM, Gardea-Torresdey JL (2012) Applications of synchrotron $\mu$-XRF to study the distribution of biologically important elements in different environmental matrices: a review. Anal Chim Acta 755:1-16

28. Niemiec MJ, De Samber B, Garrevoet J, Vergucht E, Vekemans B, De Rycke R, Björn E, Sandblad L, Wellenreuther G, Falkenberg G, Cloetens P, Vincze L, Urban CF (2015) Trace element landscape of resting and activated human neutrophils on the submicrometer level. Metallomics 7:996-1010

29. Pushie MJ, Pickering IJ, Korbas M, Hackett MJ, George GN (2014) Elemental and chemically specific X-ray fluorescence imaging of biological systems. Chem Rev 114:8499-8541

30. Simon R, Buth G, Hagelstein M (2003) The X-ray fluorescence facility at ANKA, Karlsruhe: minimum detection limits and micro probe capabilities. Nucl Instrum Meth B 199:554-558

31. Solé VA, Papillon E, Cotte M, Walter P, Susini J (2007) A multiplatform code for the analysis of energy-dispersive X-ray fluorescence spectra. Spectrochim Acta B 62:63-68

32. Stein A, Van der Meer F, Gorte B (eds) (2002) Spatial statistics for remote sensing. Kluwer Academic Publishers, New York

33. Steinbrenner H, Sies H (2009) Protection against reactive oxygen species by selenoproteins. Biochim Biophys Acta 1790:1478-1485

34. Facecchia K, Fochesato LA, Ray SD, Stohs SJ, Pandey S (2011) Oxidative toxicity in neurodegenerative diseases: role of mitochondrial dysfunction and therapeutic strategies. J Toxicol 2011:683728

35. Schweizer U, Bräuer AU, Köhrle J, Nitsch R, Savaskan NE (2004) Selenium and brain function: a poorly recognized liaison. Brain Res Brain Res Rev 45:164-178 
36. Ashrafi MR, Shabanian R, Abbaskhanian A, Nasirian A, Ghofrani M, Mohammadi M, Zamani GR, Kayhanidoost Z, Ebrahimi S, Pourpak Z (2007) Selenium and intractable epilepsy: is there any correlation? Pediatr Neurol 36:25-29

37. Ramaekers VT, Calomme M, Vanden Berghe D, Makropoulos W (1994) Selenium deficiency triggering intractable seizures. Neuropediatrics 25:217-223

38. Weber GF, Maertens P, Meng XZ, Pippenger CE (1991) Glutathione peroxidase deficiency and childhood seizures. Lancet 337:1443-1444

39. Willmore LJ, Rubin JJ (1991) Antiperoxidant pretreatment and iron-induced epileptiform discharges in the rat: EEG and histopathologic studies. Neurology 31:63-69

40. Oztaş B, Kiliç S, Dural E, Ispir T (2001) Influence of antioxidants on the blood-brain barrier permeability during epileptic seizures. J Neurosci Res 66:674-678

41. Mattson MP, Liu D (2003) Mitochondrial potassium channels and uncoupling proteins in synaptic plasticity and neuronal cell death. Biochem Biophys Res Commun 304:539-549

42. Horvath TL, Diano S, Barnstable C (2003) Mitochondrial uncoupling protein 2 in the central nervous system: neuromodulator and neuroprotector. Biochem Pharmacol 65:1917-1921

43. Hawkes CP, Levine MA (2014) Ketotic hypercalcemia: a case series and description of a novel entity. J Clin Endocrinol Metab 99:1531-1536

44. Fujikawa DG (2005) Prolonged seizures and cellular injury: understanding the connection. Epilepsy Behav 7:3-11

45. Scorza FA, Arida RM, Naffah-Mazzacoratti Mda G, Scerni DA, Calderazzo L, Cavalheiro EA (2009) The pilocarpine model of epilepsy: what have we learned? An Acad Bras Cienc $81: 345-365$
46. Kosonowska E, Janeczko K, Setkowicz Z (2015) Inflammation induced at different developmental stages affects differently the range of microglial reactivity and the course of seizures evoked in the adult rat. Epilepsy Behav 49:66-70

47. Takeda A (2000) Movement of zinc and its functional significance in the brain. Brain Res Brain Res Rev 34:137-148

48. Gower-Winter SD, Levenson CW (2012) Zinc in the central nervous system: from molecules to behavior. BioFactors 38:186-193

49. Itoh M, Ebadi M (1982) The selective inhibition of hippocampal glutamic acid decarboxylase in zinc-induced epileptic seizures. Neurochem Res 7:1287-1298

50. Chung SH, Johnson MS (1983) Divalent transition-metal ions $\left(\mathrm{Cu}^{2+}\right.$ and $\left.\mathrm{Zn}^{2+}\right)$ in the brains of epileptogenic and normal mice. Brain Res 280:323-334

51. Morton JD, Howell GA, Frederickson CJ (1990) Effects of subcutaneous injections of zinc chloride on seizures induced by noise and by kainic acid. Epilepsia 31:139-144

52. Fukahori M, Itoh M (1990) Effects of dietary zinc status on seizure susceptibility and hippocampal zinc content in the El (epilepsy) mouse. Brain Res 529:16-22

53. Vamecq J, Vallee L, Lesage F, Gressens P, Stables JP (2005) Antiepileptic popular ketogenic diet: emerging twists in an ancient story. Prog Neurobiol 75:1-28

54. Chwiej J, Skoczen A, Janeczko K, Kutorasinska J, Matusiak K, Figiel H, Dumas P, Sandt C, Setkowicz Z (2015) The biochemical changes in hippocampal formation occurring in normal and seizure experiencing rats as a result of a ketogenic diet. Analyst 140:2190-2204 